\title{
Study on Morphology, Rheology, and Mechanical Properties of Poly(trimethylene terephthalate)/ $\mathrm{CaCO}_{3}$ Nanocomposites
}

\author{
Jian Wang, Chunzheng Wang, and Mingtao Run \\ College of Chemistry and Environmental Science, Hebei University, Baoding, Hebei 071002, China \\ Correspondence should be addressed to Mingtao Run; lhbx@hbu.cn
}

Received 29 April 2013; Accepted 21 June 2013

Academic Editor: Giridhar Madras

Copyright (C) 2013 Jian Wang et al. This is an open access article distributed under the Creative Commons Attribution License, which permits unrestricted use, distribution, and reproduction in any medium, provided the original work is properly cited.

\begin{abstract}
For preparing good performance polymer materials, poly(trimethylene terephthalate) $/ \mathrm{CaCO}_{3}$ nanocomposites were prepared and their morphology, rheological behavior, mechanical properties, heat distortion, and crystallization behaviors were investigated by transmission electron microscopy, capillary rheometer, universal testing machine, impact tester, heat distortion temperature tester, and differential scanning calorimetry (DSC), respectively. The results suggest that the nano- $\mathrm{CaCO}_{3}$ particles are dispersed uniformly in the polymer matrix. $\mathrm{PTT} / \mathrm{CaCO}_{3}$ nanocomposites are pseudoplastic fluids, and the $\mathrm{CaCO}_{3}$ nanoparticles serve as a lubricant by decreasing the apparent viscosity of the nanocomposites; however, both the apparent viscosity and the pseudoplasticity of the nanocomposites increase with increasing $\mathrm{CaCO}_{3}$ contents. The nanoparticles also have nucleation effects on PTT's crystallization by increasing the crystallization rate and temperature; however, excessive nanoparticles will depress this effect because of the agglomeration of the particles. The mechanical properties suggest that the $\mathrm{CaCO}_{3}$ nanoparticles have good effects on improving the impact strength and tensile strength with proper content of fillers. The nanofillers can greatly increase the heat distortion property of the nanocomposites.
\end{abstract}

\section{Introduction}

Poly(trimethylene terephthalate) (PTT), as shown in Scheme 1 , is a thermoplastic aromatic polyester. PTT offers several advantageous properties, including good tensile strength, resilience, outstanding elastic recovery, and dyeability, which makes it an ideal candidate for applications in textile fiber, carpet, and engineering plastic [1-4]. However, if it serves as an engineering plastic material, PTT still has some shortcomings, such as poor impact resistance at lower temperatures and low heat distortion temperature; thus, the modification of PTT with the other kind of polymers or fillers has been widely developed by researchers $[5,6]$.

Inorganic particulate nanofillers have been employed to improve the properties and/or lower costs of the polymer products. Generally, nanosized fillers are superior to their micron-sized counterparts in improving the mechanical and thermal properties of thermoplastics because of their larger interfacial area between the particles and the surrounding polymer matrix [7-9]. Various nanoinorganic particles, such as $\mathrm{TiO}_{2}[10,11]$, calcium carbonate $\left(\mathrm{CaCO}_{3}\right)$ $[12-18], \mathrm{SiO}_{2}[19,20]$, and clay [21-25], are usually used as fillers in the organic/inorganic composites. $\mathrm{CaCO}_{3}$ has been one of the most commonly used inorganic fillers for the thermoplastics such as poly(vinyl chloride) and polypropylene. There are many efforts devoting to surfacemodified particles to increase the interactions between the polymers and fillers, that is, stearic acid [13], titanate [15], poly(oxyethylene nonylphenol) [16], chlorinated polyethylene [17], and cetyltrimethyl ammonium chloride [24]. The effects of surface modification on the mechanical properties have been positive [16, 26, 27].

In the present work, in order to improve the mechanical and thermal properties of the PTT, PTT/ $\mathrm{CaCO}_{3}$ nanocomposites were prepared by melt blending and characterized in terms of their morphology, rheological behavior, mechanical properties, heat distortion temperature, crystallization, and subsequent melting behaviors by various experimental measurements. The tri(dioctylpyrophosphateoxy) titanate was used as a modifier to treat $\mathrm{CaCO}_{3}$ to avoid the agglomeration. 


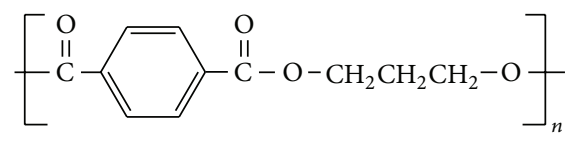

Scheme 1: Molecular formula of PTT.

\section{Experimental}

2.1. Raw Materials. PTT homopolymer was supplied in pellet form by Shell Chemicals (USA) with weight-average molecular masses $\left(M_{w}\right)$ of 100,400 and molecular polydispersity $\left(M_{w} / M_{n}\right)$ of 2.1 , and its intrinsic viscosity was $0.92 \mathrm{dL} / \mathrm{g}$ measured in a phenol/tetrachloroethane solution $(50 / 50, \mathrm{w} / \mathrm{w})$ at $25^{\circ} \mathrm{C}$. The $\mathrm{CaCO}_{3}$ nanoparticles were supplied by Guangxi Chemical, Ltd. (China) with a particle size in the range of 50$70 \mathrm{~nm}$. A nonionic modifier tri(dioctylpyrophosphateoxy) titanate (CT-114), which had good stability under $285^{\circ} \mathrm{C}$, was supplied by Jiangsu Lijin Chemical, Ltd. (Changzhou, China). In order to reduce the surface free energy of the $\mathrm{CaCO}_{3}$ and increase the surface interactions between nanoparticles and PTT, the $\mathrm{CaCO}_{3}$ nanoparticles were modified by the tri(dioctylpyrophosphateoxy) titanate in the following method: $\mathrm{CaCO}_{3}$ nanoparticles were dried in an oven at $110^{\circ} \mathrm{C}$ for $8 \mathrm{~h}$ before being modified; titanate, dissolved with ethanol $(1: 1 \mathrm{w} / \mathrm{w})$, was added to the dried $\mathrm{CaCO}_{3}$ with a weight ratio of titanate: $\mathrm{CaCO}_{3}$ was 3.3/100; then the mixture was stirred for $10 \mathrm{~min}$ with a high-speed mixer and then heated in an oven at $60^{\circ} \mathrm{C}$ for $3 \mathrm{~h}$ to promote the reaction; finally, the modified nano- $\mathrm{CaCO}_{3}$ was washed in ethanol three times then filtrated and dried at $100^{\circ} \mathrm{C}$ in an oven for $3 \mathrm{~h}$.

2.2. Nanocomposites Preparation. PTT was dried in a vacuum oven at $120^{\circ} \mathrm{C}$ for $12 \mathrm{~h}$ before preparing the blends. The dried PTT pellets and the modified $\mathrm{CaCO}_{3}$ nanoparticles were mixed together with different weight ratios of $\mathrm{PTT} / \mathrm{CaCO}_{3}$ as follows: C0: 100/0; C1: 99/1; C2: 98/2; C4: 96/4; C6: 94/6; C8: 92/8; C20: 80/20; C30: 70/30; the mixture were melt-blended for $10 \mathrm{~min}$ in a high-speed mixer and then transferred to a ZSK-25WLE type twin-screw extruder (WP Co. Germany) with five heating cells, operating at a screw speed of $100 \mathrm{rpm}$ and with temperatures of $210,235,250,255,255$, and $250^{\circ} \mathrm{C}$ from the first cell to the die. The resultant blend ribbons were cooled in cold water, cut into pellets, and redried before being used in measurements.

2.3. Morphological Characterizations. The dispersion state of the nano- $\mathrm{CaCO}_{3}$ particles in the polymer matrix was examined with a Hitachi 900 transmission electron microscopy (TEM, Hitachi, Japan) at an accelerating voltage of $10 \mathrm{kV}$.

2.4. Rheological Characterizations. The rheological behaviors of different PTT/ $\mathrm{CaCO}_{3}$ nanocomposites were determined with an XLY-II type capillary rheometer (Jilin University Sci. \& Edu. Instrument Co., China) equipped with the capillary length of $40 \mathrm{~mm}$ and the diameter of $1 \mathrm{~mm}$. The sample weights were about $1.5 \mathrm{~g}$, and the specific temperatures were set from 235 to $250^{\circ} \mathrm{C}$ with the shearing stress in the range of $18-129 \mathrm{kPa}$. The samples were added into the capillary and then heated to specific temperature, held for $10 \mathrm{~min}$, and then their rheological behaviors were tested at different stress.

2.5. Mechanical Properties Testing. The normative splines used in mechanical properties testing were all prepared by a microinjection molding machine (SZ-15, Wuhan Ruiming Machinery, China) at the cylinder temperature of $255^{\circ} \mathrm{C}$ and mold temperature of $20^{\circ} \mathrm{C}$. The tensile strength testing was done according to the ISO 3167-2002/A standard on the computer controlled electronic universal material machine (WSM20, Changchun Intelligent Sci. \& Techn. Co. Ltd., China). The impact tests were carried out according to the ISO 179-1982 standard using a Charpy impact tester (JJ5.5, Changchun Intelligent Instrument Co. Ltd., China) with unnotched type sample; the data reported were the mean and standard deviation from five determinations.

2.6. Differential Scanning Calorimetry Characterizations. The melt-crystallization and subsequent melting behaviors of the various nanocomposites were performed on a differential scanning calorimetry (Diamond DSC, Perkin-Elmer Co., USA) and the weight of samples were approximately $7.0 \mathrm{mg}$. The dried samples were heated to $260^{\circ} \mathrm{C}$ at $80^{\circ} \mathrm{C} / \mathrm{min}$ under a nitrogen atmosphere, held for $5 \mathrm{~min}$ to release the thermal history, and then cooled to $50^{\circ} \mathrm{C}$ at a constant cooling rate of $10^{\circ} \mathrm{C} / \mathrm{min}$, held for $3 \mathrm{~min}$, and finally heated again to $260^{\circ} \mathrm{C}$ at a rate of $10^{\circ} \mathrm{C} / \mathrm{min}$; the first cooling and subsequent melting processes were recorded.

2.7. Heat Distortion Temperature Characterizations. The heat distortion temperatures (HDT) of the blends were tested by using a heat distortion temperature tester (WKW-300, Changchun Intelligent Instrument Co. Ltd., China) at the pressure of $1.82 \mathrm{MPa}$ and a heating rate of $50 \pm 0.5^{\circ} \mathrm{C} / \mathrm{h}$; The samples with size of $10 \times 10 \times 10 \mathrm{~mm}$ were injection molded using a microinjection molding machine (SZ-15, Wuhan Ruiming Machinery, China) at cylinder temperature of $255^{\circ} \mathrm{C}$ and mold temperature of $65^{\circ} \mathrm{C}$; the data reported were the mean and standard deviation from two determinations.

\section{Results and Discussion}

3.1. Morphology. The micrographs of $\mathrm{C} 1, \mathrm{C} 2, \mathrm{C} 4$, and $\mathrm{C} 8$ performed on TEM are shown in Figure 1. For $\mathrm{Cl}$ and $\mathrm{C} 2$, a good dispersion state of nano- $\mathrm{CaCO}_{3}$ particles in the matrix is observed, and no agglomeration occurs; however, for $\mathrm{C} 4$, the dispersion state of nano- $\mathrm{CaCO}_{3}$ particles is not so well, and several agglomerations with size of 200$300 \mathrm{~nm}$ are observed, which are several times larger than the primary size of $50-70 \mathrm{~nm}$; for $\mathrm{C} 8$, most of the nano- $\mathrm{CaCO}_{3}$ particles are dispersed well, but many bigger agglomerations with size of $300-400 \mathrm{~nm}$ are observed in the matrix. These results indicate that the shear force given by melt extrusion was not enough to break down all of the agglomerations especially at relatively high filler concentrations (e.g., 8\%). The agglomeration of nano- $\mathrm{CaCO}_{3}$ may affect the properties of PTT nanocomposites. 


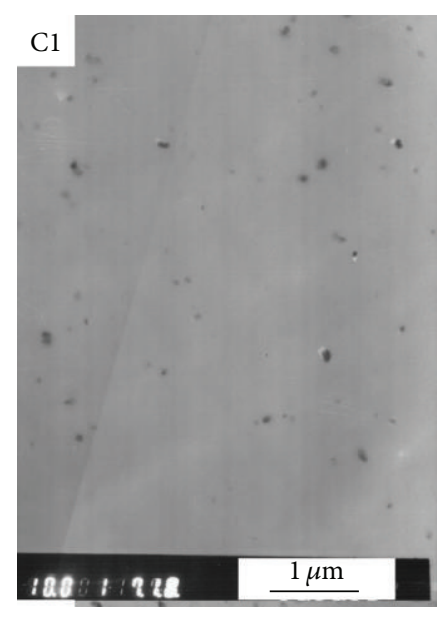

(a)

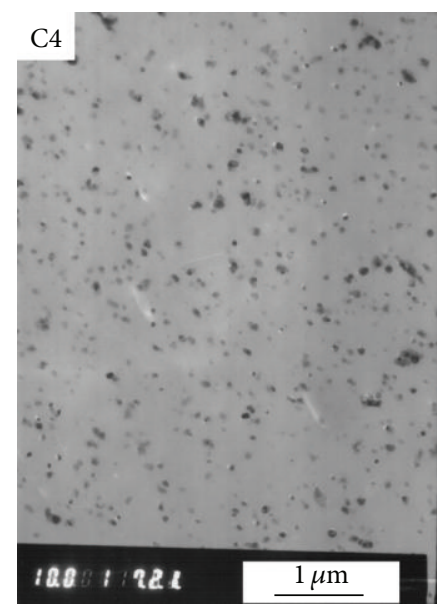

(c)

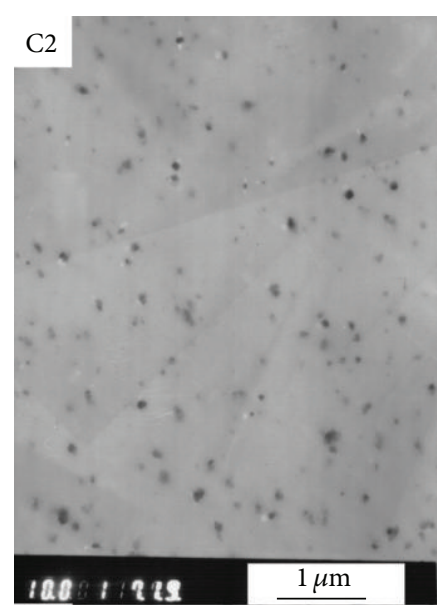

(b)

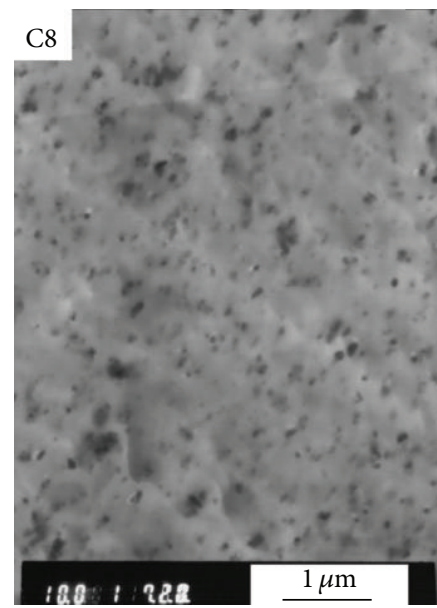

(d)

FIgURE 1: Transmission electron micrographs of nanocomposites C1, C2, C4, and C8.

TABLE 1: Mechanical properties and heat distortion temperatures of different $\mathrm{PTT} / \mathrm{CaCO}_{3}$ nanocomposites.

\begin{tabular}{|c|c|c|c|c|c|}
\hline Sample & $\sigma_{b}^{\mathrm{a}} / \mathrm{MPa}$ & $E^{\mathrm{b}} / \mathrm{GPa}$ & $\varepsilon_{b}^{c} / \%$ & $\sigma_{i}^{\mathrm{d}} / \mathrm{kJ} \cdot \mathrm{m}^{-2}$ & $\mathrm{HTD} /{ }^{\circ} \mathrm{C}$ \\
\hline $\mathrm{C} 0$ & $68.4 \pm 0.8$ & $2.11 \pm 0.01$ & $75.0 \pm 0.8$ & $6.5 \pm 0.2$ & $60.5 \pm 0.2$ \\
\hline $\mathrm{C} 1$ & $76.0 \pm 1.1$ & $2.49 \pm 0.01$ & $82.2 \pm 0.6$ & $11.5 \pm 0.2$ & $67.2 \pm 0.2$ \\
\hline $\mathrm{C} 2$ & $78.3 \pm 0.9$ & $2.55 \pm 0.01$ & $88.4 \pm 0.4$ & $14.7 \pm 0.1$ & $75.6 \pm 0.1$ \\
\hline $\mathrm{C} 4$ & $79.9 \pm 1.2$ & $2.62 \pm 0.02$ & $95.7 \pm 0.8$ & $16.4 \pm 0.2$ & $82.8 \pm 0.1$ \\
\hline $\mathrm{C} 8$ & $72.7 \pm 0.8$ & $2.96 \pm 0.01$ & $99.1 \pm 0.5$ & $20.1 \pm 0.3$ & $93.4 \pm 0.2$ \\
\hline $\mathrm{C} 20$ & $66.7 \pm 0.9$ & $3.01 \pm 0.01$ & $74.1 \pm 0.4$ & $18.8 \pm 0.2$ & $105.1 \pm 0.2$ \\
\hline $\mathrm{C} 30$ & $63.4 \pm 0.7$ & $3.09 \pm 0.02$ & $64.6 \pm 0.5$ & $9.5 \pm 0.1$ & $108.2 \pm 0.1$ \\
\hline
\end{tabular}

a: tensile strength.

b: elastic modulus.

c: breaking elongation.

d: impact strength.

3.2. Mechanical and Heat Distortion Properties. The influences of nano- $\mathrm{CaCO}_{3}$ contents on the mechanical properties of different nanocomposites are shown in Table 1. The tensile strength slightly increases first and then decreases gradually with increasing $\mathrm{CaCO}_{3}$ content and reaches maximum as $\mathrm{CaCO}_{3}$ content is $4 \%$. The nanocomposites' elongation at rupture and unnotched impact strength first increase rapidly and reach maximum as $\mathrm{CaCO}_{3}$ content is $8 \%$, then reduce gradually and reach minimum as $\mathrm{CaCO}_{3}$ content is $30 \%$. The elastic modulus constantly increases with the increasing $\mathrm{CaCO}_{3}$ content. When $\mathrm{CaCO}_{3}$ content is $8 \%$, the nanocomposites' elastic modulus increases $43.6 \%$ and the 
unnotched impact strength increases near $209.2 \%$ than that of the matrix. The improved impact strength suggests that the inorganic nano-particles have good interface with the matrix resin, and the nanoparticles can make the matrix to produce plastic deformations and/or crazes to absorb plentiful energy when the material undergoes stress. The nano-particles can produce stress hardening effect by making the elastic modulus increase constantly. The decreasing of tensile strength and impact strength with more than $8 \%$ $\mathrm{CaCO}_{3}$ content may be caused by the agglomerations of the $\mathrm{CaCO}_{3}$ particles in the nanocomposites.

The heat distortion temperatures (HDT) of different nanocomposites are also shown in Table 1 . It can be seen that the HDT increases with increasing $\mathrm{CaCO}_{3}$ particles, suggesting that $\mathrm{CaCO}_{3}$ particles have good effect on improving the thermal resistance of PTT.

3.3. Rheological Behaviors. The length-diameter ratio of the capillary used in this test is $40: 1$, so the melt flow in this capillary can be seen as steady state flow when the shearing stress is small, ignoring the end effect. The apparent viscosity of the melt is calculated by the Hagen-Poiseuille equation [28]. The relationship between the apparent viscosity $\left(\eta_{a}\right)$ and the shearing rate of the nanocomposites at $235^{\circ} \mathrm{C}$ is shown in Figure 2. At low shearing rate range $\left(\ln \dot{\gamma}_{w}<5\right)$, the $\ln \eta_{a}$ of various nanocomposites are nearly unchanged with increasing shearing rate, belonging to the Newtonian fluid; while at high shearing rate range $\left(\ln \dot{\gamma}_{w}>5\right)$, the $\ln \eta_{a}$ of various nanocomposites decreases sharply with increasing shearing rate, belonging to the pseudoplastic fluid, due to the disentanglements between the molecular chains or between the molecular chains and nanoparticles. This result suggests that we can control the processing viscosity of the melts by controlling the shearing rate.

Although the various nanocomposites have the similar rheological curves with increasing shearing rate, their apparent viscosity are quite different with increasing $\mathrm{CaCO}_{3}$ contents. Chen et al. [29] had studied the influences of nano- $\mathrm{CaCO}_{3}$ on the rheological behavior of polypropylene, and found that the viscosity decreased with increasing filler amount after being added with $\mathrm{CaCO}_{3}$ treated with proper amount of surface treatment agent (i.e., stearic acid). But in this work, when PTT was added with nano- $\mathrm{CaCO}_{3}$ (treated with titanate), a different trend appears: comparing the apparent viscosities of the various nanocomposites, we can find that the apparent viscosity increases with increasing $\mathrm{CaCO}_{3}$ content from $1 \%$ to $30 \%$. However, the apparent viscosity of pure PTT is only smaller than that of the nanocomposite with $30 \% \mathrm{CaCO}_{3}$, and the nanocomposite with $1 \% \mathrm{CaCO}_{3}$ has the smallest viscosity. When the PTT was melt blended with $\mathrm{CaCO}_{3}$ treated with titanate, the nano- $\mathrm{CaCO}_{3}$ particles will exist between different PTT molecular chains, and it can form some physical or chemical connections (such as polar interactions) with PTT molecules which interactions can reduce the flexibility of molecular chains and the concentration of entanglement points in the melt; moreover, small amount of $\mathrm{CaCO}_{3}$ can serve as a lubrication and reduce the interaction force between PTT molecular chains and

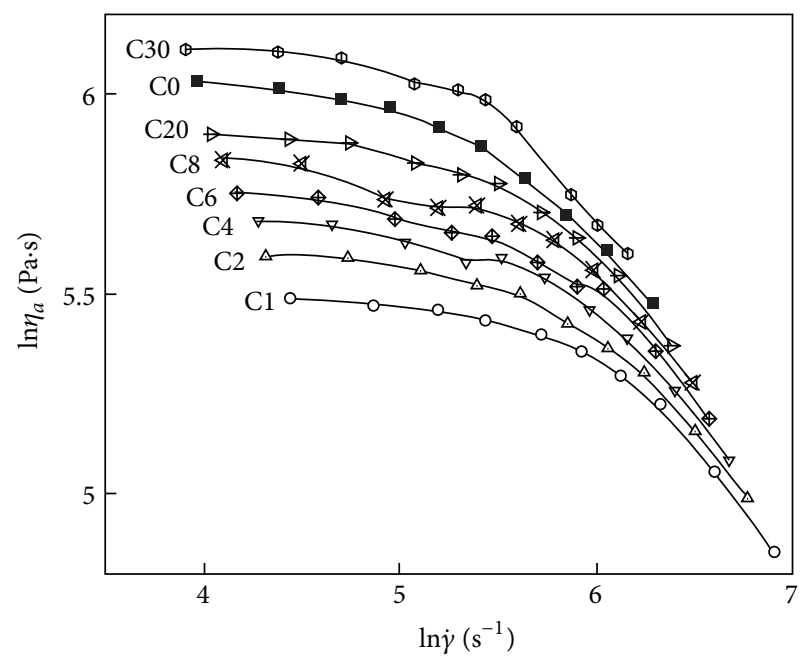

FIgURE 2: Relationship between the apparent viscosity and shearing rate of the various $\mathrm{PTT} / \mathrm{CaCO}_{3}$ nanocomposites.

flow resistance, and thus the melt apparent viscosity of this nanocomposite is much lower than that of pure PTT. With the increasing $\mathrm{CaCO}_{3}$ content from $2 \%$ to $20 \%$, the melt viscosity increases gradually with the increasing nanoparticle contents, but they are still lower than that of pure PTT, indicating that the $\mathrm{CaCO}_{3}$ nanoparticles primarily serve as lubricant and play a role of reducing chain's entanglement, while the frictional resistance between different fillers plays a minor role; but as the nanoparticle content increases much (when the $\mathrm{CaCO}_{3}$ content is $30 \%$ ), the nanoparticle density in matrix increases sharply, so the agglomerate chance of the particles increases correspondingly, and the strong friction force between particles plays a primary role on increasing the melt viscosity, so the melt viscosity is higher than that of pure PTT.

The melt's non-Newtonian fluid index, $n$, another important parameter to measure melt rheological behavior, is calculated by the Ostwald-Dewaele Equation [30],

$$
\ln \tau_{w}=\ln K+n \ln \dot{\gamma}_{w}
$$

We can get the $n$ from the slopes in the pseudoplastic region of $\ln \tau_{w}$ versus $\ln \dot{\gamma}_{w}$ curves. The dependence of $n$ on the $\mathrm{CaCO}_{3}$ content in the composites is shown in Figure 3. Generally, the more flexible are the polymer chains, the more entanglement points will they have, and it is more difficult for the chains to untangle and slip. The value of $n$ is smaller if the polymer's pseudoplastic is stronger. By using X-ray and electronic diffraction, Poulin-Dandurand et al. [31] found that although PTT backbone chains had benzene rings which had stronger rigidity, the $-\mathrm{O}-\mathrm{CH}_{2}-\mathrm{CH}_{2}-\mathrm{CH}_{2}-\mathrm{O}-$ unit in them had a trans-gauche-gauche-trans conformation which had the lowest energy, the obvious " $Z$ " pattern conformation made the PTT backbone chains possess elasticity that is easy to deform. Under a force, the conformation transformed from "gauche" to "trans" and the molecular chains elongated easily, so its $n$ value was small. After adding $\mathrm{CaCO}_{3}$ nanoparticles, they act as a lubricant and reduce the entanglements between 


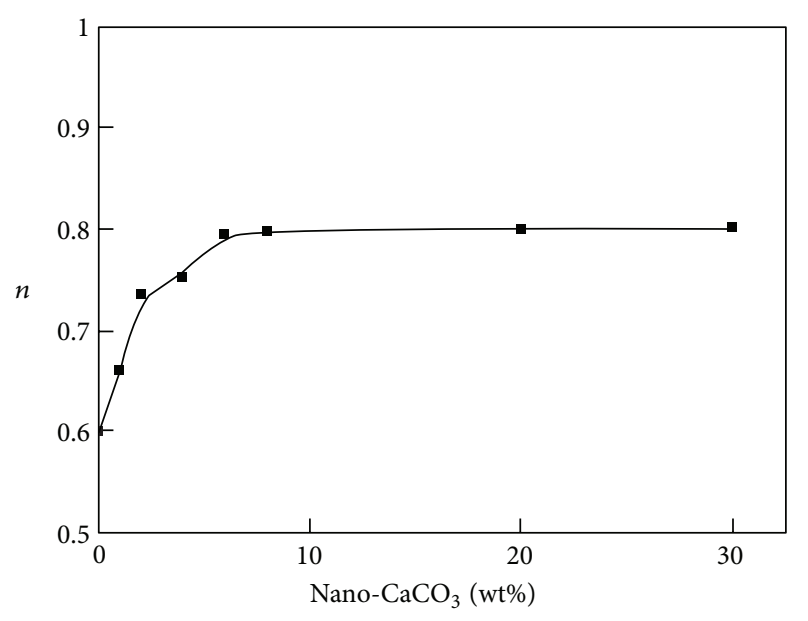

Figure 3: Relationship between $n$ and $\mathrm{CaCO}_{3} \mathrm{wt} \%$ in nanocomposites.

molecular chains, so the pseudoplasticity reduces and the $n$ increases with increasing $\mathrm{CaCO}_{3}$ content. In Figure 3, $n$ increases rapidly when $\mathrm{CaCO}_{3}$ content is $0-6 \%$, while it levels off with more than $8 \%$ of $\mathrm{CaCO}_{3}$ content; we believe that the lubricant effect of nano- $\mathrm{CaCO}_{3}$ reaches saturation when its content is beyond $8 \%$.

The relationships between $\eta_{a}$ and $\mathrm{CaCO}_{3}$ wt $\%$ in composites at different temperatures are shown in Figure 4. At the same temperature, $\eta_{a}$ first decreases and then increases with increasing $\mathrm{CaCO}_{3}$ content; at various temperatures, $\eta_{a}$ decreases with increasing temperatures, indicating that the processing properties of the nanocomposites is dependent on the temperature. Also it can be seen from Figure 4 that different nanocomposites' viscosity changes very differently with increasing temperatures; for example, when the temperatures increase from $235^{\circ} \mathrm{C}$ to $250^{\circ} \mathrm{C}$, the $\eta_{a}$ of the nanocomposite with $30 \% \mathrm{CaCO}_{3}$ content reduces $50 \%$ (decreasing from $518 \mathrm{~Pa} \cdot s$ to $257 \mathrm{~Pa} \cdot \mathrm{s}$ ); while the $\eta_{a}$ of the nanocomposite with $1 \% \mathrm{CaCO}_{3}$ content reduces $38 \%$ (decreasing from $238 \mathrm{~Pa} \cdot \mathrm{s}$ to $147 \mathrm{~Pa} \cdot \mathrm{s}$ ). This result suggests that the composites with different $\mathrm{CaCO}_{3}$ contents have different sensitivities to the temperatures.

The dependence of $\eta_{a}$ on the temperature (T) could be expressed by using the Andrade equation as follows:

$$
\ln \eta_{a}=\ln A+\left(-\frac{\Delta E_{\eta}}{R T}\right)
$$

where $\Delta E_{\eta}$ is the apparent flow activation energy whose unit is $\mathrm{KJ} \cdot \mathrm{mol}^{-1}, R$ is the gas constant whose unit is $\mathrm{J} \cdot \mathrm{K}^{-1} \cdot \mathrm{mol}^{-1}$, $T$ is the absolute temperature whose unit is $K$, and $A$ is a constant. $\Delta E_{\eta}$ is used to describe the sensitivity of the $\eta_{a}$ to the temperature, and $\Delta E_{\eta}$ increases if the molecular chains' rigidity is enhanced [32].

The $\Delta E_{\eta}$ can be calculated according to the slopes of $\ln \eta_{a}$ versus $1 / T$ curves, as shown in Figure 5. It can be seen that $\Delta E_{\eta}$ increases with increasing $\mathrm{CaCO}_{3}$ contents. Generally, the good interface combination between the nano-particles and the matrix can reduce the flexibility and enhance the

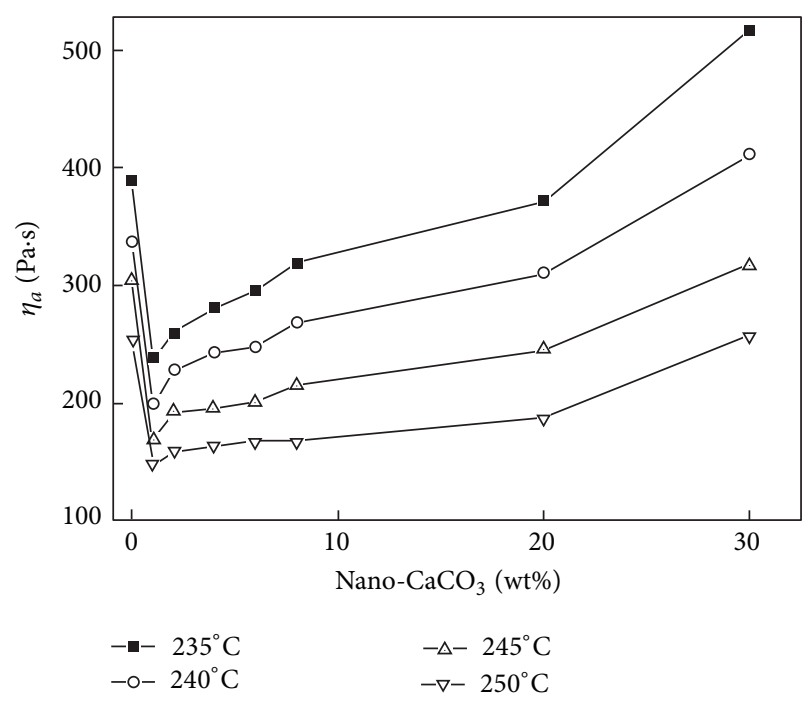

FIgURE 4: Relationship between $\eta_{a}$ and $\mathrm{CaCO}_{3} \mathrm{wt} \%$ in nanocomposites at different temperatures.

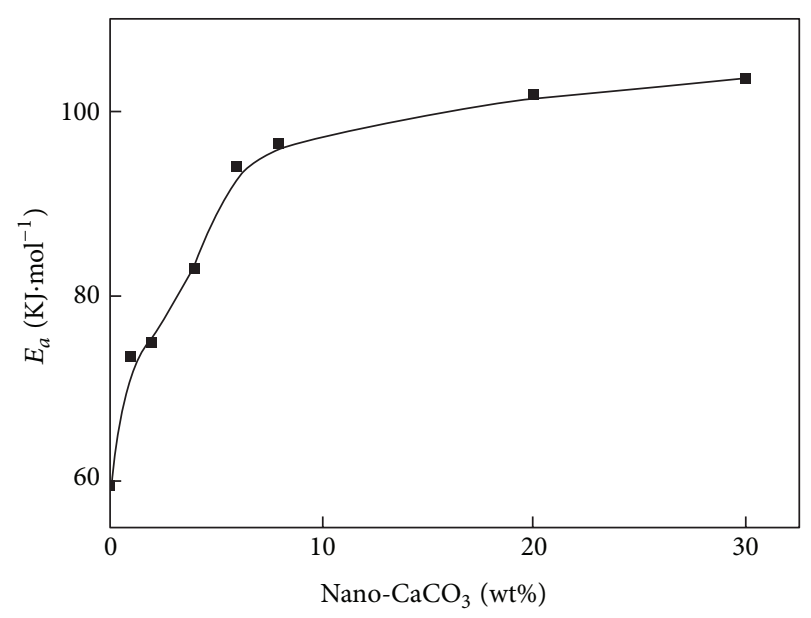

Figure 5: Relationship between $\Delta E_{\eta}$ and $\mathrm{CaCO}_{3} \mathrm{wt} \%$ in nanocomposites.

rigidity of polymer molecular chains, so the $\Delta E_{\eta}$ increases as well as the sensitivity of melt viscosity to the temperature. Inorganic particles have strong rigidity, and the polymer has better flexibility, so adding inorganic particles to the polymer systems can rapidly increase the melt rigidity, thus the flow activation energy increases quickly. Also it can be seen from Figure 5 that $\Delta E_{\eta}$ increases fast when the $\mathrm{CaCO}_{3}$ content is 0 $6 \%$, while it increases slowly with $8-30 \%$ of $\mathrm{CaCO}_{3}$ contents; this is also a saturation effect with too much of $\mathrm{CaCO}_{3}$.

\subsection{Melt-Crystallization and Subsequent Melting Behaviors.} The DSC melt-crystallization curves for different PTT/ $\mathrm{CaCO}_{3}$ nanocomposites are shown in Figure 6, and the resulting parameters are listed in Table 2. Generally speaking, the introduction of proper amount of nucleating agents will promote the polymer crystallization, including the increase 
TABLE 2: DSC parameters of different PTT/ $\mathrm{CaCO}_{3}$ nanocomposites.

\begin{tabular}{|c|c|c|c|c|c|c|c|}
\hline \multirow{2}{*}{ Sample } & \multicolumn{4}{|c|}{ Cooling process } & \multicolumn{3}{|c|}{ Heating process } \\
\hline & $T_{\mathrm{cl}} /{ }^{\circ} \mathrm{C}$ & $T_{\mathrm{c} 2} /{ }^{\circ} \mathrm{C}$ & $F W H P /{ }^{\circ} \mathrm{C}$ & $\Delta H_{\mathrm{c}} / \mathrm{J} \cdot \mathrm{g}^{-1}$ & $T_{\mathrm{rc}}{ }^{\circ} \mathrm{C}$ & $T_{\mathrm{m}} /{ }^{\circ} \mathrm{C}$ & $\Delta H_{\mathrm{m}} / \mathrm{J} \cdot \mathrm{g}^{-1}$ \\
\hline $\mathrm{CO}$ & 177.6 & - & 10.91 & -50.5 & - & 224.9 & 65.9 \\
\hline $\mathrm{Cl}$ & 185.1 & - & 6.97 & -51.9 & 214.4 & 229.6 & 57.2 \\
\hline $\mathrm{C} 2$ & 181.2 & - & 6.73 & -48.2 & 210.1 & 229.7 & 59.9 \\
\hline $\mathrm{C} 4$ & 181.7 & - & 7.64 & -51.7 & 211.1 & 228.5 & 59.2 \\
\hline C6 & 183.4 & - & 8.19 & -52.4 & 211.4 & 227.8 & 56.5 \\
\hline $\mathrm{C} 8$ & 184.3 & 180.6 & 9.94 & -50.9 & 213.0 & 230.1 & 56.6 \\
\hline $\mathrm{C} 20$ & 187.6 & 180.8 & 12.37 & -56.1 & 214.1 & 229.1 & 59.1 \\
\hline $\mathrm{C} 30$ & 186.7 & 180.9 & 9.75 & -51.1 & 213.1 & 227.7 & 52.7 \\
\hline
\end{tabular}

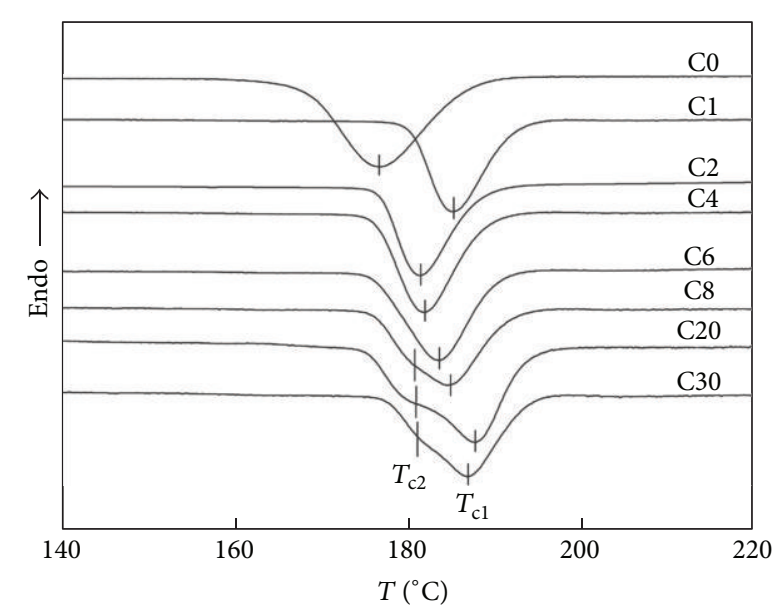

FIGURE 6: DSC melt-crystallization curves for different PTT/CaCO 3 nanocomposites.

of the starting crystallization temperature and the crystallization rate of the polymer, which will make it easier to crystallize. As we can see from Figure 6 and Table 2, the crystallization peak temperatures $\left(T_{c}\right)$ of the nanocomposites are all higher than that of pure PTT, indicating that the nano$\mathrm{CaCO}_{3}$ particles, acting as the nuclei, have an heterogeneous nucleation effect on PTT crystallization, thus PTT molecular chains can begin to crystallize at higher temperatures with the $\mathrm{CaCO}_{3}$ nuclei. However, the nanocomposites with different $\mathrm{CaCO}_{3}$ contents have different $T_{\mathrm{c}}$. The nanocomposite of $\mathrm{Cl}$ has single crystallization peak with a $T_{\mathrm{c}}$ at $185.1^{\circ} \mathrm{C}$, while $\mathrm{C} 2$, C4, and C6 have single crystallization peaks with lower $T_{c} \mathrm{~S}$ in the range of $181-183^{\circ} \mathrm{C}$; but for $\mathrm{C} 8, \mathrm{C} 20$, and $\mathrm{C} 30$, each of them has double crystallization peaks with $T_{\mathrm{c} 1}$ and $T_{\mathrm{c} 2}$, the lower is around $180^{\circ} \mathrm{C}$, the higher is around $186^{\circ} \mathrm{C}$. The multiple crystallization peaks are the reorganization of the crystallites where filler particles have disrupted crystal growth. It can be concluded that when the $\mathrm{CaCO}_{3}$ content is $1 \%$, the nucleation effect is apparent due to the nanodispersed particles; while for the nanocomposites $\mathrm{C} 8-\mathrm{C} 30$, although some nanodispersed $\mathrm{CaCO}_{3}$ particles have apparent nucleation effect, some agglomerates of $\mathrm{CaCO}_{3}$ particles disrupt the crystal growth; thus, the molecular chain segments reorganize and form some microcrystallites adjacent the former crystals, and

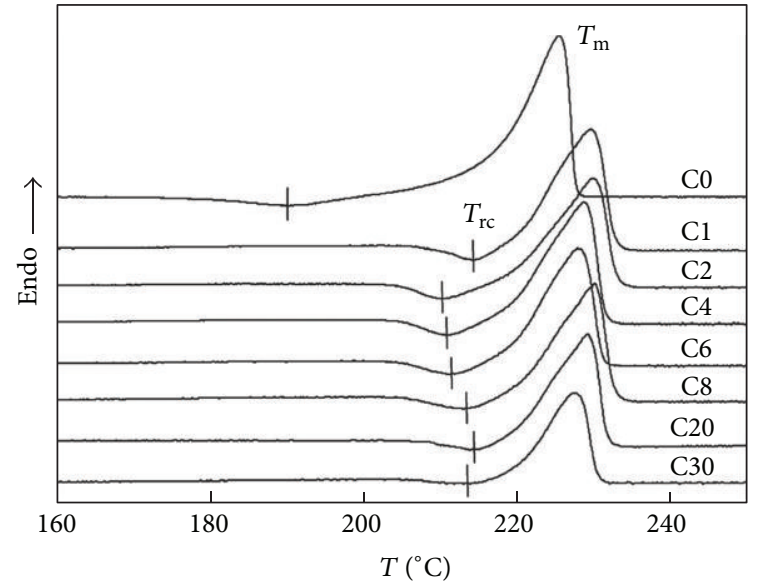

FIgURE 7: DSC melting curves for different $\mathrm{PTT} / \mathrm{CaCO}_{3}$ nanocomposites.

their corresponding DSC curves show both a higher $T_{\mathrm{c} 2}$ and a lower $T_{\mathrm{c} 1}$. Moreover, the full width at half height of the crystallization peak (FWHP) decreases as the nanoparticles content increases, especially when the $\mathrm{CaCO}_{3}$ contents were $0-2 \%$; however, the FWHP values increase with further increasing $\mathrm{CaCO}_{3}$ contents (4-30\%). This result suggests that the nanocomposite with $2 \% \mathrm{CaCO}_{3}$ has the fastest meltcrystallization rate among these nanocomposites.

The subsequent melting DSC curves of the above samples are shown in Figure 7, and the parameters are listed in Table 2. In Figure 7, the nanocomposites also show higher melting temperatures $\left(T_{\mathrm{m}}\right)$ than that of pure PTT. The changes law of $T_{\mathrm{m}} \mathrm{s}$ with increasing $\mathrm{CaCO}_{3}$ particles is similar to that of $T_{\mathrm{c}}$. C1 has much higher $T_{\mathrm{m}}$ than that of $\mathrm{C} 0$, while $\mathrm{C} 2, \mathrm{C} 4$, and $\mathrm{C} 6$ have a little lower $T_{\mathrm{m}}$ than that of $\mathrm{Cl}$; but $\mathrm{C} 8$ and C20 have higher $T_{\mathrm{m}} \mathrm{s}$ than that of $\mathrm{C} 6$, and C30 has a close value of $T_{\mathrm{m}}$ with C6. These changing $T_{\mathrm{m}} \mathrm{s}$ are dependent on the $T_{\mathrm{c}} \mathrm{s}$. Moreover, a recrystallization peak $\left(T_{\mathrm{rc}}\right)$ can be seen in each DSC curve, which is changed with increasing $\mathrm{CaCO}_{3}$ content. Also, the changing law of $T_{\mathrm{rc}}$ is similar to those changing law of $T_{\mathrm{c}}$ and $T_{\mathrm{m}}$. The different values of $T_{\mathrm{c}} \mathrm{s}, T_{\mathrm{m}} \mathrm{s}$, and $T_{\mathrm{rc}}$ of different nanocomposites suggest that the crystals formed after melt-crystallization have different dimensions and lamellar thickness $[33,34]$. 
It can also be seen from the Table 2 that the introduction of $\mathrm{CaCO}_{3}$ particles can reduce the nanocomposites' normalized melting enthalpy $\left(\Delta H_{\mathrm{m}}\right)$ because the crystal growth space will be limited with the increasing content of $\mathrm{CaCO}_{3}$ nucleus, which leads to form more imperfect spherulites in the nanocomposites; in addition, as we can see from the former rheology data, the melt viscosity increases as the $\mathrm{CaCO}_{3}$ content increases, and the mobility of the PTT molecular chains decreases, and the fillers disrupt the crystal growth; thus, the crystallization degree and the subsequent $\Delta H_{\mathrm{m}}$ decrease.

\section{Conclusions}

PTT/CaCO 3 nanocomposites' melt belongs to the pseudoplastic fluid, and the pseudoplasticity increases with the increasing $\mathrm{CaCO}_{3}$ content. The $\mathrm{CaCO}_{3}$ nanoparticles serve as a lubricant in the nanocomposites that decrease the melt apparent viscosity obviously with only $1 \%$ content; however, the melt viscosity increases gradually with increasing $\mathrm{CaCO}_{3}$ content from $1 \%$ to $30 \%$. When the concentration of $\mathrm{CaCO}_{3}$ is below $4 \%$, the nanoparticles disperse uniformly in the matrix. The $\mathrm{CaCO}_{3}$ nanoparticles act as nucleus for the meltcrystallization of the nanocomposites, and it increases the start-crystallization temperature and the crystallization rate of the nanocomposites although large content of $\mathrm{CaCO}_{3}$ particles will depress the nucleation effect. The $\mathrm{CaCO}_{3}$ nanocomposites also have both reinforcement and toughening effects on the PTT matrix, in which $2-8 \%$ contents of $\mathrm{CaCO}_{3}$ nanoparticles are preferred for improving both the impact strength and the tensile strength. The $\mathrm{CaCO}_{3}$ particles have good effect on improving the thermal resistance of PTT.

\section{Acknowledgments}

The work is supported by the financial support from the Natural Science Foundation of Hebei Province (B2010000219) and the Undergraduate Science and Technology Innovation Foundation of Hebei University (2012065).

\section{References}

[1] J.-M. Huang, M.-Y. Ju, P. P. Chu, and F.-C. Chang, "Crystallization and melting behaviors of poly(trimethylene terephthalate)," Journal of Polymer Research, vol. 6, no. 4, pp. 259-266, 1999.

[2] J. L. Zhang, "Study of poly(trimethylene terephthalate) as an engineering thermoplastics material," Journal of Applied Polymer Science, vol. 91, no. 3, pp. 1657-1666, 2004.

[3] J.B. Bernard, L. Menachem, and K. Jongsoo, "Crystallization kinetics of poly(propylene terephthalate) studied by rapidscanning Raman spectroscopy and FT-IR spectroscopy," Macromolecules, vol. 20, no. 4, pp. 830-835, 1987.

[4] N. Apiwanthanakorn, P. Supaphol, and M. Nithitanakul, "Nonisothermal melt-crystallization kinetics of poly(trimethylene terephthalate)," Polymer Testing, vol. 23, no. 7, pp. 817-826, 2004.

[5] D. R. Paul and C. B. Bucknall, Polymer Blends, WileyInterscience, 2000.
[6] L. A. Utracki, Polymer Blends Handbook, Kluwer Academic, Dodrecht, The Netherlands, 2003.

[7] P. B. Messersmith and E. P. Giannelis, "Synthesis and barrier properties of poly(e-caprolactone)-layered silicate nanocomposites," Journal of Polymer Science A, vol. 33, no. 7, pp. 10471057, 1995.

[8] K. Yano, A. Usuki, A. Okada, T. Kurauchi, and O. Kamigaito, "Synthesis and cationic photopolymerization of alkoxyallene monomers," Journal of Polymer Science A, vol. 31, no. 14, pp. 2493-2504, 1993.

[9] E. Butta, G. Levita, A. Marchetti, and A. Lazzeri, "Morphology and mechanical properties of amine-terminated butadieneacrylonitrile/epoxy blend," Polymer Engineering and Science, vol. 26, no. 1, pp. 63-73, 1986.

[10] Z. Wang, G. Li, G. Xie, and Z. Zhang, "Dispersion behavior of $\mathrm{TiO}_{2}$ nanoparticles in LLDPE/LDPE/TiO ${ }_{2}$ nanocomposites," Macromolecular Chemistry and Physics, vol. 206, no. 2, pp. 258262, 2005.

[11] Y. Liu, J. Y. Lee, and L. Hong, "Morphology, crystallinity, and electrochemical properties of in situ formed poly(ethylene oxide) $/ \mathrm{TiO}_{2}$ nanocomposite polymer electrolytes," Journal of Applied Polymer Science, vol. 89, no. 10, pp. 2815-2822, 2003.

[12] M. Z. Rong, M. Q. Zhang, Y. X. Zheng, H. M. Zeng, R. Walter, and K. Friedrich, "Structure-property relationships of irradiation grafted nano-inorganic particle filled polypropylene composites," Polymer, vol. 42, no. 1, pp. 167-183, 2001.

[13] A. Lazzeri, S. M. Zebarjad, M. Pracella, K. Cavalier, and R. Rosa, "Filler toughening of plastics. Part 1: the effect of surface interactions on physico-mechanical properties and rheological behaviour of ultrafine $\mathrm{CaCO}_{3} / \mathrm{HDPE}$ nanocomposites," Polymer, vol. 46, no. 3, pp. 827-844, 2005.

[14] X.-L. Xie, Q.-X. Liu, R. K.-Y. Li et al., "Rheological and mechanical properties of $\mathrm{PVC} / \mathrm{CaCO}_{3}$ nanocomposites prepared by in situ polymerization," Polymer, vol. 45, no. 19, pp. 6665-6673, 2004.

[15] Y. Tang, Y. Hu, R. Zhang et al., "Investigation into poly (propylene)/montmorillonite/calcium carbonate nanocomposites," Macromolecular Materials and Engineering, vol. 289, no. 2, pp. 191-197, 2004.

[16] Q.-X. Zhang, Z.-Z. Yu, X.-L. Xie, and Y.-W. Mai, “Crystallization and impact energy of polypropylene $/ \mathrm{CaCO}_{3}$ nanocomposites with nonionic modifier," Polymer, vol. 45, no. 17, pp. 5985-5994, 2004.

[17] D. Wu, X. Wang, Y. Song, and R. Jin, "Nanocomposites of poly(vinyl chloride) and nanometric calcium carbonate particles: effects of chlorinated polyethylene on mechanical properties, morphology, and rheology," Journal of Applied Polymer Science, vol. 92, no. 4, pp. 2714-2723, 2004.

[18] M. Run, C. Yao, Y. Wang, and J. Gao, "Isothermal crystallization kinetics and melting behaviors of nanocomposites of poly(trimethylene terephthalate) filled with nano- $\mathrm{CaCO}_{3}$," Journal of Applied Polymer Science, vol. 106, no. 3, pp. 1557-1567, 2007.

[19] R. Petrovicova, R. Knight, L. S. Schadler, and T. E. Twadowski, "Nylon11/silica nanocomposite coatings applied by the HVOF process. II. Mechanical and barrier properties," Journal of Applied Polymer Science, vol. 78, no. 13, pp. 2272-2289, 2000.

[20] N. Hasegawa, H. Okamoto, M. Kato, and A. Usaki, "Preparation and mechanical properties of polypropylene-clay hybrids based on modified polypropylene and organophilic clay," Journal of Applied Polymer Science, vol. 78, no. 11, pp. 1918-1922, 2000. 
[21] C.-S. Wu, "Synthesis of polyethylene-octene elastomer $/ \mathrm{SiO}_{2}$ $\mathrm{TiO}_{2}$ nanocomposites via in situ polymerization: Properties and characterization of the hybrid," Journal of Polymer Science A, vol. 43, no. 8, pp. 1690-1701, 2005.

[22] J. M. Hwu, G. J. Jiang, Z. M. Gao, W. Xie, and W. P. Pan, “The characterization of organic modified clay and clay-filled PMMA nanocomposite," Journal of Applied Polymer Science, vol. 83, no. 8, pp. 1702-1710, 2002.

[23] X. Hu and A. J. Lesser, "Effect of a silicate filler on the crystal morphology of poly(trimethylene terephthalate)/clay nanocomposites," Journal of Polymer Science B, vol. 41, no. 19, pp. 2275-2289, 2003.

[24] C.-F. Ou, "Crystallization behavior and thermal stability of poly(trimethylene terephthalate)/clay nanocomposites," Journal of Polymer Science B, vol. 41, no. 22, pp. 2902-2910, 2003.

[25] X. Hu and A. J. Lesser, "Non-isothermal crystallization of poly(trimethylene terephthalate) (PTT)/clay nanocomposites," Macromolecular Chemistry and Physics, vol. 205, no. 5, pp. 574580, 2004.

[26] M. Guessoum, S. Nekkaa, F. Fenouillot-Rimlinger, and N. Haddaoui, "Effects of Kaolin surface treatments on the thermomechanical properties and on the degradation of polypropylene," International Journal of Polymer Science, vol. 2012, Article ID 549154, 9 pages, 2012.

[27] J. González, C. Albano, M. Ichazo, and B. Díaz, "Effects of coupling agents on mechanical and morphological behavior of the PP/HDPE blend with two different $\mathrm{CaCO}_{3}$," European Polymer Journal, vol. 38, no. 12, pp. 2465-2475, 2002.

[28] E. Tamaki, A. Hibara, H.-B. Kim, M. Tokeshi, and T. Kitamori, "Pressure-driven flow control system for nanofluidic chemical process," Journal of Chromatography A, vol. 1137, no. 2, pp. 256262, 2006.

[29] X.-Y. Chen, G. Wang, W.-Y. Fan, and R. Huang, "Study on unusual rheological behavior of polyolefin/nano $\mathrm{CaCO}_{3} \mathrm{com}$ posites," China Plastics, vol. 17, no. 5, pp. 57-63, 2003.

[30] D. H. Hang, Rheology in Polymer Processing, New York Academic Press, New York, NY, USA, 1976.

[31] S. Poulin-Dandurand, S. Pérez, J.-F. Revol, and F. Brisse, "The crystal structure of poly(trimethylene terephthalate) by X-ray and electron diffraction," Polymer, vol. 20, no. 4, pp. 419-426, 1979.

[32] J. A. Brydson, Flow Properties of Polymer Melts, Van Nostrand Reinhold, New York, NY, USA, 1970.

[33] X. F. Lu and J. N. Hay, "Isothermal crystallization kinetics and melting behaviour of poly(ethylene terephthalate)," Polymer, vol. 42, no. 23, pp. 9423-9431, 2001.

[34] Y. Kong and J. N. Hay, "Multiple melting behaviour of poly(ethylene terephthalate)," Polymer, vol. 44, no. 3, pp. 623633, 2003. 

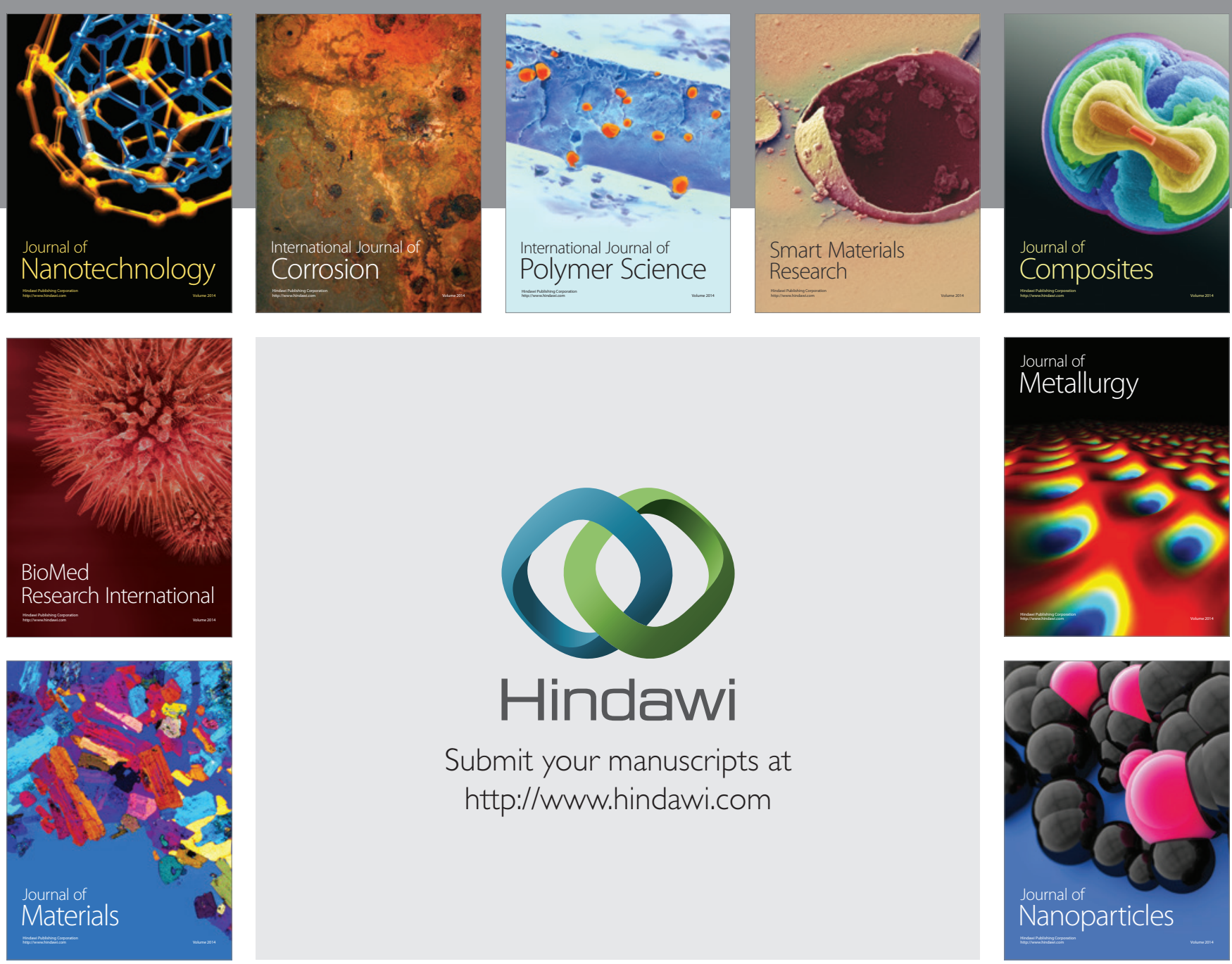

Submit your manuscripts at http://www.hindawi.com
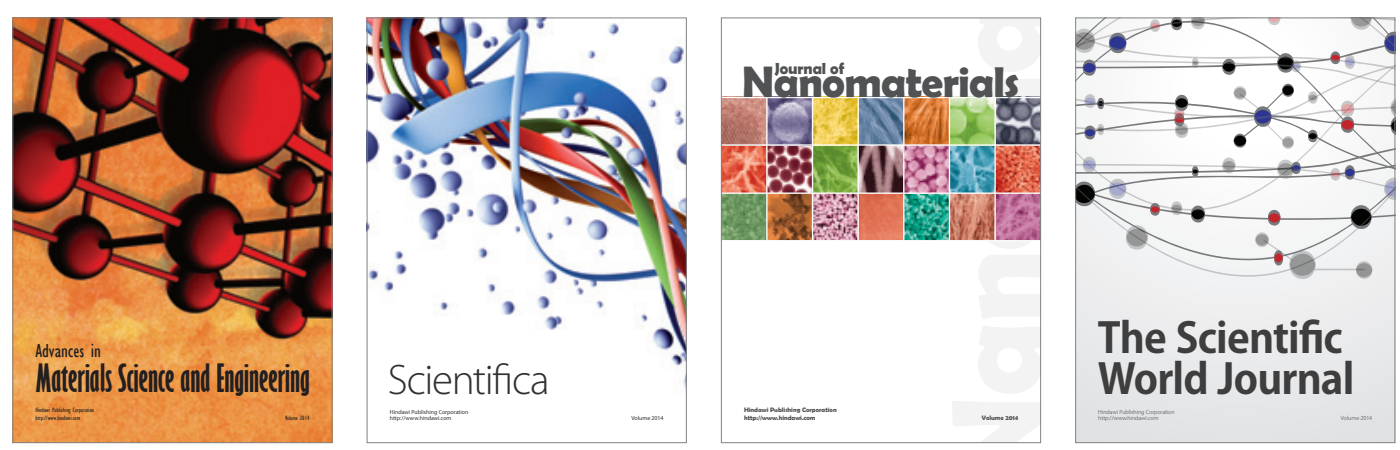

\section{The Scientific World Journal}
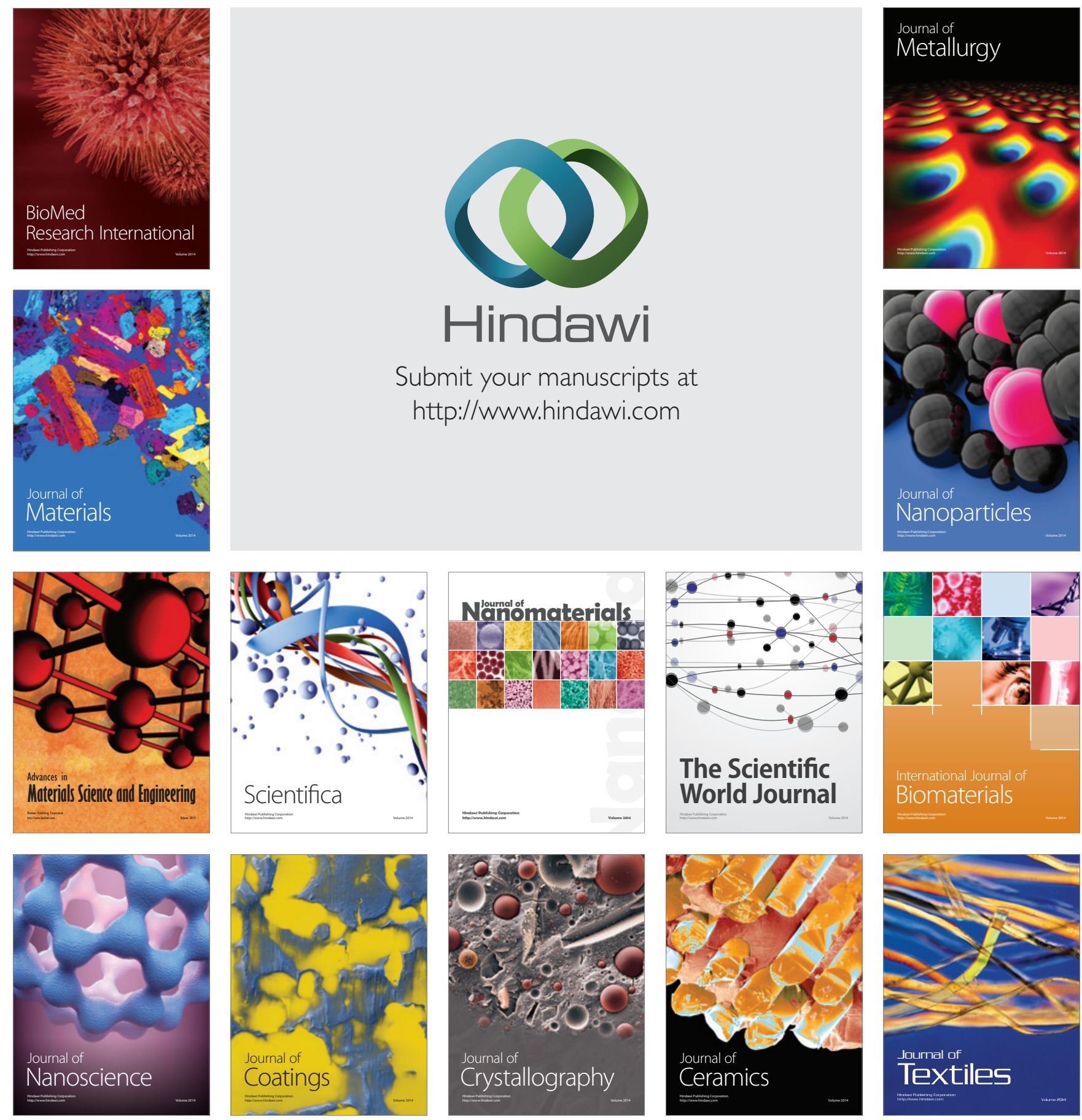